\title{
Exhaled Nitric Oxide in Systemic Sclerosis Lung Disease
}

\author{
Natalie K. Kozij, ${ }^{1}$ John T. Granton, ${ }^{1}$ Philip E. Silkoff, ${ }^{2}$ John Thenganatt, ${ }^{1}$ \\ Shobha Chakravorty, ${ }^{3}$ and Sindhu R. Johnson ${ }^{4}$ \\ ${ }^{1}$ University Health Network Pulmonary Hypertension Programme, Toronto General Hospital, Department of Medicine, \\ University of Toronto, Toronto, ON, Canada \\ ${ }^{2}$ Department of Medicine, Temple University, Philadelphia, PA, USA \\ ${ }^{3}$ University Health Network Pulmonary Hypertension Programme, Toronto General Hospital, Toronto, ON, Canada \\ ${ }^{4}$ University Health Network Pulmonary Hypertension Programme, Toronto General Hospital, Toronto Scleroderma Program, \\ Toronto Western Hospital, Mount Sinai Hospital, Department of Medicine, Institute of Health Policy, Management and Evaluation, \\ University of Toronto, Toronto, ON, Canada
}

Correspondence should be addressed to Sindhu R. Johnson; sindhu.johnson@uhn.ca

Received 28 September 2016; Revised 9 December 2016; Accepted 9 January 2017; Published 14 February 2017

Academic Editor: Djuro Kosanovic

Copyright (C) 2017 Natalie K. Kozij et al. This is an open access article distributed under the Creative Commons Attribution License, which permits unrestricted use, distribution, and reproduction in any medium, provided the original work is properly cited.

\begin{abstract}
Background. Exhaled nitric oxide (eNO) is a potential biomarker to distinguish systemic sclerosis (SSc) associated pulmonary arterial hypertension (PAH) and interstitial lung disease (ILD). We evaluated the discriminative validity, feasibility, methods of eNO measurement, and magnitude of differences across lung diseases, disease-subsets (SSc, systemic lupus erythematosus), and healthy-controls. Methods. Consecutive subjects in the UHN Pulmonary Hypertension Programme were recruited. Exhaled nitric oxide was measured at $50 \mathrm{~mL} / \mathrm{s}$ intervals using chemiluminescent detection. Alveolar and conducting airway NO were partitioned using a two-compartment model of axial diffusion (CMAD) and the trumpet model of axial diffusion (TMAD). Results. Sixty subjects were evaluated. Using the CMAD model, control subjects had lower median (IQR) alveolar NO than all PAH subjects $(2.0(1.5,2.5)$ versus $3.14 \mathrm{ppb}(2.3,4.0), p=0.008)$. SSc-ILD had significantly lower median conducting airway NO compared to controls (1009.5 versus $1342.1 \mathrm{ml} * \mathrm{ppb} / \mathrm{s}, p=0.04)$. SSc-PAH had increased median (IQR) alveolar NO compared to controls (3.3 $(3.0,5.7)$ versus $2.0 \mathrm{ppb}(1.5,2.5), p=0.01)$. SSc-PAH conducting airway NO inversely correlated with DLCO $(r-0.88$ (95\% CI $-0.99,-0.26)$ ). Conclusion. We have demonstrated feasibility, identified that CMAD modeling is preferred in SSc, and reported the magnitude of differences across cases and controls. Our data supports discriminative validity of eNO in SSc lung disease.
\end{abstract}

\section{Introduction}

Pulmonary arterial hypertension (PAH) and interstitial lung disease (ILD) are serious manifestations of systemic sclerosis (SSc). Previous reports suggest that $\mathrm{PAH}$ develops in approximately $7 \%$ of these patients and is a leading cause of death $[1,2]$. Studies have examined exhaled nitric oxide (eNO) as a marker of pulmonary hypertension in SSc [3-9]. NO is derived from the amino acid arginine and synthesized by the enzyme NO synthase (NOS). NO is a potent vasodilator which stimulates the production of cyclic $3^{\prime} 5^{\prime}$-monophosphate (cGMP), resulting in smooth muscle relaxation [10]. The exact source of eNO is uncertain but likely represents a mixture of NO derived from the alveolar surface and from airway epithelial cells [11]. To date, studies examining the potential role of eNO as a marker in SSc$\mathrm{PAH}$ have suggested decreased eNO or alveolar $\mathrm{NO}\left(C_{A} \mathrm{NO}\right)$, compared to individuals with SSc alone $[3,6,8,9]$. In SScILD, studies have suggested that eNO or $C_{A} \mathrm{NO}$ is increased compared to control subjects, particularly if active alveolitis is present $[3,8,12-15]$. As a prognostic marker, $C_{A} \mathrm{NO}$ levels may predict the occurrence of a $10 \%$ decrease in total lung capacity or forced vital capacity or death in patients with SSc [16].

This body of work suggests that exhaled nitric oxide may be a useful measure for use in SSc longitudinal observational studies or clinical trials. Indeed, there have been calls for novel methods to study SSc lung disease in clinical research 
[17]. However, important aspects of exhaled nitric oxide as a measure need to be ascertained prior to its implementation in the design of studies, including feasibility, the preferred method of measuring exhaled nitric oxide, and estimates of the magnitude of differences between cases and controls. The aim of this study was to evaluate exhaled nitric oxide as an outcome measure in SSc lung disease. The objective was to evaluate the discriminative validity of eNO in SSc lung disease. We also assessed the ability to recruit patients and conduct eNO measurements in the clinical setting. Given perioral skin tightening in SSc, we wanted to evaluate the feasibility of conducting these measurements in SSc subjects. We secondarily wanted to comparatively evaluate methods of measuring eNO to identify the preferred method. We evaluated the magnitude of differences across lung diseases (PAH, ILD, and both), and patient subsets (SSc, diseasecontrol subjects (systemic lupus erythematosus (SLE), IPAH), and healthy-control subjects) to inform sample size and power estimates. The demonstration of feasibility, estimates of magnitude of differences between cases and controls, and demonstrable discriminative validity are all necessary prerequisites of a measure for its implementation as an outcome measure in clinical trials and observational studies.

\section{Materials and Methods}

2.1. Subjects. The University Health Network Pulmonary Hypertension Program (Toronto General Hospital, Toronto, ON, Canada) is the largest published longitudinal pulmonary hypertension cohort in Canada [18]. All patients undergo a standardized visit at least twice a year, including physical exam, laboratory testing, and investigations (CT thorax, echocardiogram, pulmonary function testing, serum BNP, cardiac catheterization, and six-minute walk test) as appropriate. The Toronto Scleroderma Program (Toronto Western Hospital, Mount Sinai Hospital, Toronto, ON, Canada) is the largest single-center SSc cohort in Canada [19]. All patients undergo a standardized visit every 6-12 months, including physical exam, laboratory testing, pulmonary function testing, and transthoracic echocardiography. Consecutive patients attending either program were screened by their physician or by the pulmonary function technician for study participation.

Subjects were included if they were $>18$ years, classified as SSc (American College of Rheumatology (ACR)European League Against Rheumatism classification criteria for systemic sclerosis) [20] or SLE (ACR classification criteria for SLE) [21, 22], had mPAP > $25 \mathrm{mmHg}$ on right-heart catheterization [23], and/or ILD based on a CT thorax ILD score $>5 \%$ [24] and normal left ventricular function on echocardiogram. Subjects were excluded if they were pregnant, had HIV, congenital cardiac abnormalities, or had grade 2 left ventricular dysfunction or higher on echocardiogram.

2.2. Exhaled Nitric Oxide. Exhaled NO was measured using the Sievers GE 280i Nitric Oxide Analyser (Boulder, Colorado). Patients were instructed to inhale maximally (room air) and exhale against resistance to achieve continuous flow rates of $50,100,150,200$, and $250 \mathrm{~mL} / \mathrm{min}$. Patients had a visual marker indicating when they had achieved the desired flow rate. Exhaled NO was assessed for each flow rate on a separate exhalation. $F_{E} \mathrm{NO}$ values at each flow rate are the mean of three plateau values on the $F_{E} \mathrm{NO}$ time curves. The plateau values were determined by the Sievers' Analyser algorithm. Exhaled concentrations of $\mathrm{NO}$ at each flow rate were compared between each group and controls (Model 1). In addition, the two-compartment model of axial diffusion (CMAD) was used [7, 25-29]. The following calculation was used to partition alveolar $\left(C_{A}\right)$ versus conducting airway $\left(J_{\mathrm{awNO}}^{\prime}\right)$ components of the respiratory tract (Model 2):

$$
V_{\mathrm{NO}}=C_{A} \times V_{\text {exh }}+J_{\mathrm{awNO}}^{\prime}=F_{E} \mathrm{NO} \times V_{\text {exh }},
$$

where $V_{\mathrm{NO}}$ is $\mathrm{NO}$ output $(\mathrm{pL} / \mathrm{s}), C_{A}$ is steady state alveolar concentration of NO (ppb), $V_{\text {exh }}$ is flow rate $(\mathrm{mL} / \mathrm{s}), J_{\text {awNO }}^{\prime}$ is total molar flux of NO in nanolitres/s (at an infinite $V_{\text {exh }}$ ) in $\mathrm{nL} / \mathrm{s}, F_{E} \mathrm{NO}$ is exhaled $\mathrm{NO}$ concentration ( $\mathrm{ppb}$ ), and $\mathrm{Ppb}$ is $\mathrm{nL} / \mathrm{L}\left(1 \times 10^{-9}\right)$.

$C_{A}$ was determined by calculating the slope of the line, and $J_{\text {awNO }}^{\prime}$ was determined by the $y$-intercept when multiple flow rates are assessed:

$$
\begin{aligned}
C_{A} & =\text { slope } \\
& =\frac{\left(V_{\mathrm{NO}}-J_{\mathrm{NO}}\right)}{V_{\mathrm{exh}}}=F_{E} \mathrm{NO}-\frac{J_{\mathrm{NO}}}{V_{\mathrm{exh}}} \\
J_{\mathrm{awNO}}^{\prime} & =y-\text { intercept }=V_{\mathrm{NO}}-\left(C_{A} \times V_{\mathrm{exh}}\right) .
\end{aligned}
$$

A third approach (Model 3) using the trumpet model of axial diffusion (TMAD) corrects for the trumpet shape of the lungs (increasing surface area per unit volume) and the gas phase axial diffusion. In the initial derivation studies by Condorelli et al. [30], the alveolar concentration $C_{A}$ was statistically lower, with $J_{\text {awNO }}^{\prime}$ being statistically higher compared to the CMAD. The correction factors in the trumpet model were

$$
\begin{aligned}
C_{A} & =\text { slope }-\left(\frac{y \text {-intercept }}{740} \mathrm{~mL} / \mathrm{s}\right) \\
J_{\text {awNO }}^{\prime} & =1.7 \times(y \text {-intercept }) .
\end{aligned}
$$

2.3. BNP. Serum BNP measurements were obtained using the Bayer Centaur chemiluminescent assay (normal range $\leq$ $99.9 \mathrm{pg} / \mathrm{mL})$.

2.4. CT Thorax. All participants underwent CT thorax. CT scans were reviewed by a blinded respirologist (JT). The extent of ILD ( $0 \%-100 \%$ using 5\% intervals) was measured at 5 thoracic levels: the origin of the great vessels; the main carina; the pulmonary venous confluence; halfway between the third and fifth sections; and immediately above the right hemidiaphragm. The scores at each level were averaged to create a single score. This score was used to stage the severity of ILD using a validated SSc-ILD staging system [24]. A HRCT score $\leq 10 \%$ or HRCT of $11-30 \%$ (termed indeterminate) and FVC $\geq 70 \%$ was staged as limited disease. A HRCT score $>30 \%$ or HRCT of $11-30 \%$ and FVC $<70 \%$ was staged as extensive disease. 
2.5. Data Administration. Connective tissue disease diagnosis, comorbidities, diagnostic tests, medications (prednisone, nonsteroidal anti-inflammatories), and smoking status were collected from the electronic health record or clinic chart(s) by a single abstractor. Data were double-entered into a computerized database.

2.6. Ethics, Consent, and Permissions. This study was approved by the Research Ethics Board of the University Health Network (reference number 12-5777 AE) [31]. Subjects provided written informed consent.

2.7. Statistical Analysis. Descriptive statistics were used to summarize the data. Exhaled NO was assessed using all three models. Pearson's product moment correlation coefficient and $95 \%$ confidence intervals ( $95 \% \mathrm{CI}$ ) were used to evaluate associations between eNO and serum BNP to hemodynamics, pulmonary function test parameters, and severity of ILD within and between groups. Subgroup analyses were conducted stratified by subset (SSc cases (SSc without lung disease, SSc-PAH, SSc-ILD, SSc-PAH, and ILD), disease-control subjects (SLE-PAH, IPAH), and healthy-control subjects). A $p$ value of $<0.05$ was considered statistically significant. Analyses were conducted using RStudio (version 0.98.501).

\section{Results}

3.1. Study Subjects. Sixty subjects were recruited. There were 35 SSc cases and 25 control subjects. The case mix of SSc cases included SSc subjects without lung disease $(n=16)$, SSc-PAH $(n=7)$, SSc-ILD (limited) $(n=8)$, and SSc-ILD (extensive) $(n=4)$. The median CT score was $12 \%$ for subjects with limited involvement and $38 \%$ for subjects with extensive involvement. The median disease duration from diagnosis to study recruitment for SSc subjects was 9 (range 1-32) years. The disease-control subject case mix included SLE-PAH $(n=$ $6)$ and IPAH $(n=9)$. There were 10 healthy controls. Subject characteristics are summarized in Table 1. Eighty-two percent of subjects were female. The SLE-PAH group was younger than the other groups (median age 35 years). Most subjects with SSc (89\%) had limited disease. All SSc participants had a history of Raynaud's phenomenon and none had a history of renal crisis. Most had telangiectasia (78\%), sclerodactyly (78\%), and esophageal dysmotility (72\%). In subjects with $\mathrm{PAH}$, the median mPAP ranged from 38 to $44 \mathrm{mmHg}$ and was similar between groups. The median LVEDP was also similar ranging from 6 to $9 \mathrm{mmHg}$. CT ILD scores for ILD subjects ranged between $8 \%$ and $50 \%$.

3.2. Exhaled NO. Exhaled NO values measured at a single exhalation at flow rates ranging from $50 \mathrm{~mL} / \mathrm{s}$ to $250 \mathrm{~mL} / \mathrm{s}$ did not distinguish between groups. The CMAD model identified differences in alveolar $\mathrm{NO}\left(C_{A} \mathrm{NO}\right)$ and conducting airway $\left(J_{\text {awNO }}^{\prime}\right)$ NO between groups. Healthy-control subjects had lower median (interquartile range (IQR)) alveolar NO $\left(C_{A} \mathrm{NO}\right)$ than $\mathrm{PAH}$ patients $(2.0 \mathrm{ppb}(1.5,2.5)$ versus $3.14 \mathrm{ppb}$ (2.3, 4.0), $p=0.008)$ and specifically versus SSc-PAH patients $3.3 \mathrm{ppb}(3.0,5.7), p=0.01)$ (Tables 2 and 3). SScILD patients had significantly lower median $J_{\text {awNo values }}^{\prime}$

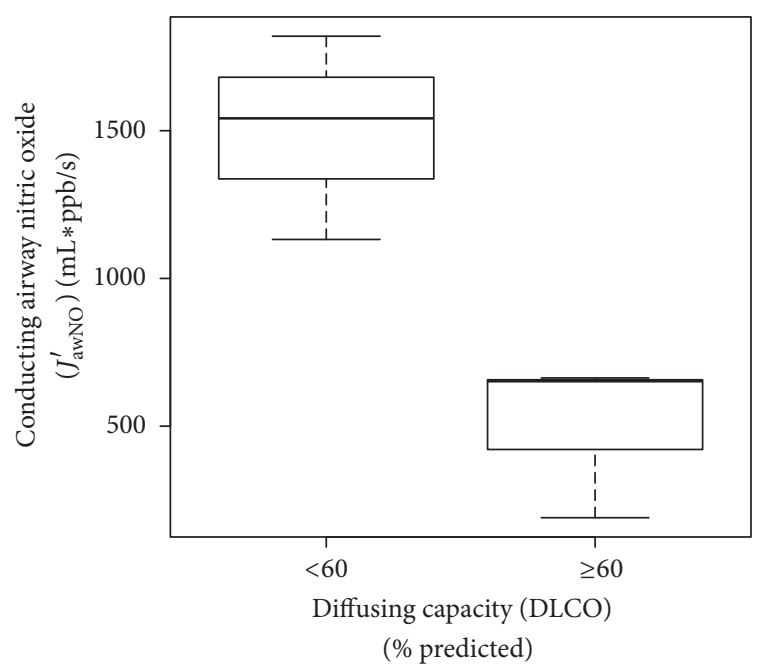

FIGURE 1: Relationship of conducting airway nitric oxide to diffusing capacity in SSc-PAH. Box plot illustrating increased conducting airway exhaled nitric oxide has discriminative validity in SSc-PAH subjects with reduced diffusing capacity.

compared to controls (1009.5 versus $1342.1 \mathrm{ml} * \mathrm{ppb} / \mathrm{s}, p=$ 0.04). Compared to all subjects with $\mathrm{PAH}$, subjects with extensive ILD appeared to have lower $C_{A} \mathrm{NO}$ (3.14 versus 2.94, $p=0.34)$ and $J_{\text {awNo }}^{\prime}(1072.4$ versus 921.6, $p=0.42)$. Compared to SLE-PAH subjects, SSc-PAH subjects appeared to have higher $C_{A} \mathrm{NO}$ (4.29 versus $2.77, p=0.13$ ) and lower $J_{\text {awNO }}^{\prime}(950.3$ versus 1177.7, $p=0.28$ ). Exploratory analyses limited to female subjects found qualitatively similar findings but were not statistically significant (Table 3 ).

The TMAD model yielded multiple negative $C_{A} \mathrm{NO}$ values, the interpretation of which is unclear (results not presented). This suggests that this modeling may not apply to patients with the diseases studied here.

Exploratory analyses evaluating the association of $C_{A} \mathrm{NO}$ and $J_{\text {awNO }}^{\prime}$ values in relation to pulmonary function testing parameters, mean pulmonary artery pressure, and right ventricular systolic function were conducted. In SSc-PAH patients, increased $J_{\text {awNO }}^{\prime}$ correlated with a reduced DLCO (Pearson's $r-0.88(95 \%$ CI $-0.99,-0.26))$. Patients with a DLCO less than $60 \%$ predicted had higher $J_{\text {awNO }}^{\prime}$ compared to those with a DLCO greater than or equal to $60 \%$ as illustrated in Figure 1.

There were no significant correlations between FVC, FEV1, and TLC with either alveolar $\mathrm{NO}\left(C_{A} \mathrm{NO}\right)$ or conducting airway $\left(J_{\text {awNO }}^{\prime}\right)$ (Tables 4-7).

3.3. Age and Sex. We found no correlation between exhaled NO and age for all subjects and subgroups (Table 7).

3.4. Serum BNP. Median serum BNP values were higher in SSc-PAH patients than SSc patients without pulmonary involvement (358.8 versus $11.6 \mathrm{pg} / \mathrm{ml}, p=0.01$ ). No other significant differences were identified between groups. 
TABLE 1: Summary of subject characteristics.

\begin{tabular}{|c|c|c|c|c|c|c|c|}
\hline & $\operatorname{SSc} n=16$ & $\begin{array}{c}\text { SSc-PAH } \\
n=7\end{array}$ & $\begin{array}{l}\text { SLE-PAH } \\
n=6\end{array}$ & $\begin{array}{c}\text { SSc-ILD limited } \\
n=8\end{array}$ & $\begin{array}{c}\text { SSc-ILD } \\
\text { extensive } n=4\end{array}$ & IPAH $n=9$ & $\begin{array}{c}\text { Control } \\
n=10\end{array}$ \\
\hline Female sex (\%) & $16(100 \%)$ & $5(71 \%)$ & $7(100 \%)$ & $7(88 \%)$ & $3(75 \%)$ & $7(78 \%)$ & $5(50 \%)$ \\
\hline Age in years (median) & 51 & 51 & 37 & 54.5 & 56.5 & 41.0 & 33.5 \\
\hline $\begin{array}{l}\text { Limited cutaneous subtype } \\
(\%)\end{array}$ & $15(94 \%)$ & $5(71 \%)$ & NA & $7(88 \%)$ & $2(50 \%)$ & NA & NA \\
\hline \multicolumn{8}{|l|}{ Manifestations (\%) } \\
\hline Calcinosis & $6(38 \%)$ & $2(29 \%)$ & NA & $1(13 \%)$ & $2(50 \%)$ & NA & NA \\
\hline Raynaud's phenomenon & $16(100 \%)$ & $7(100 \%)$ & NA & $8(100 \%)$ & $4(100 \%)$ & NA & NA \\
\hline Esophageal dysmotility & $13(81 \%)$ & $6(86 \%)$ & NA & $5(63 \%)$ & $4(100 \%)$ & NA & NA \\
\hline Sclerodactyly & $12(75 \%)$ & $6(86 \%)$ & NA & $5(63 \%)$ & $4(100 \%)$ & NA & NA \\
\hline Telangiectasia & $13(81 \%)$ & $7(100 \%)$ & NA & $5(63 \%)$ & $3(75 \%)$ & NA & NA \\
\hline Renal crisis & 0 & 0 & NA & 0 & 0 & NA & NA \\
\hline $\begin{array}{l}\text { Abnormal nailfold } \\
\text { capillaries }\end{array}$ & $5(31 \%)$ & $5(71 \%)$ & NA & $3(38 \%)$ & $2(50 \%)$ & NA & NA \\
\hline Digital ulcers & $3(19 \%)$ & $5(71 \%)$ & NA & $2(25 \%)$ & $2(50 \%)$ & NA & NA \\
\hline ScL-70 antibody & $1(6 \%)$ & 0 & NA & $2(25 \%)$ & $2(50 \%)$ & NA & $\mathrm{NA}$ \\
\hline Anti-centromere antibody & $6(38 \%)$ & $1(14 \%)$ & NA & $2(25 \%)$ & $1(25 \%)$ & NA & NA \\
\hline \multicolumn{8}{|l|}{ Hemodynamics } \\
\hline $\begin{array}{l}\text { mPAP mmHg (median, } \\
\text { IQR) }\end{array}$ & NA & $40(37-48)$ & $42(39-48)$ & NA & $38(34-40)$ & $44(42-53)$ & NA \\
\hline $\begin{array}{l}\text { LVEDP mmHg (median, } \\
\text { IQR) }\end{array}$ & NA & $8(4-10)$ & $6(6-11)$ & NA & $6(4-8)$ & $9(7-13)$ & NA \\
\hline \multicolumn{8}{|l|}{ Comorbidities (\%) } \\
\hline Asthma & $2(13 \%)$ & 0 & $2(29 \%)$ & $1(13 \%)$ & 0 & $2(22 \%)$ & 0 \\
\hline COPD & 0 & 0 & 0 & 0 & 0 & 0 & 0 \\
\hline OSA & $2(13 \%)$ & 0 & $1(14 \%)$ & $1(13 \%)$ & 0 & $1(11 \%)$ & 0 \\
\hline Systemic hypertension & $4(25 \%)$ & $1(14 \%)$ & $1(14 \%)$ & $2(25 \%)$ & $2(50 \%)$ & $3(33 \%)$ & 0 \\
\hline Atrial fibrillation & 0 & 0 & 0 & 0 & $1(25 \%)$ & 0 & 0 \\
\hline CAD & $1(6 \%)$ & $1(14 \%)$ & 0 & 0 & 0 & $1(11 \%)$ & 0 \\
\hline \multicolumn{8}{|l|}{ Smoking history (\%) } \\
\hline Current & $2(13 \%)$ & $1(14 \%)$ & 0 & 0 & 0 & 0 & NA \\
\hline Former & $6(38 \%)$ & $3(43 \%)$ & $2(29 \%)$ & $2(25 \%)$ & $2(50 \%)$ & $3(33 \%)$ & NA \\
\hline \multicolumn{8}{|l|}{ Medication (\%) } \\
\hline NSAID & $2(13 \%)$ & $2(29 \%)$ & $2(29 \%)$ & $5(63 \%)$ & 0 & $2(22 \%)$ & 0 \\
\hline Prednisone & 0 & $2(29 \%)$ & $5(71 \%)$ & $3(38 \%)$ & $2(50 \%)$ & 0 & 0 \\
\hline Inhaled corticosteroids & $1(6 \%)$ & 0 & 0 & $1(13 \%)$ & 0 & $1(11 \%)$ & 0 \\
\hline \multicolumn{8}{|l|}{ Pulmonary function tests } \\
\hline FEV1\% predicted (median) & 92.0 & 95.0 & 78.0 & 85.0 & 71.0 & 87.5 & NA \\
\hline FVC\% predicted (median) & 97.0 & 95.0 & 81.0 & 89.0 & 65.0 & 90.5 & NA \\
\hline TLC\% predicted (median) & 96 & 104 & 83 & 95 & 74 & 90 & NA \\
\hline $\begin{array}{l}\text { DLCO \% predicted } \\
\text { (median) }\end{array}$ & 72.0 & 48.5 & 73.5 & 58.0 & 65.5 & 70.5 & NA \\
\hline
\end{tabular}


TABLE 2: Comparison of exhaled nitric oxide values between groups.

\begin{tabular}{lcc}
\hline Group & $C_{A}$ NO Ppb (median) & $J_{\text {awNO }}^{\prime} \mathrm{nL} / \mathrm{s}$ (median) \\
\hline All subjects & & \\
All ILD versus controls & 2.34 versus 2.03 & $\mathbf{1 0 0 9 . 5}$ versus 1342.1 \\
All PH versus controls & $\mathbf{3 . 1 4}$ versus 2.03 & 1066.8 versus 1342.1 \\
Female subjects & & \\
All ILD versus controls & 2.30 versus 2.47 & 1065 versus 1196 \\
All PH versus controls & 3.02 versus 2.47 & 938 versus 1196 \\
\hline
\end{tabular}

Note. Bold denotes significant finding, $\mathrm{Ppb}=$ parts per billion.

\section{Discussion}

Exhaled NO is widely used as a noninvasive marker of airway inflammation in asthma; however research into its utility in scleroderma lung disease is less well developed and less well known [32]. In this study, eNO values were assessed using multiple models and demonstrated differences in exhaled alveolar $\mathrm{NO}\left(C_{A} \mathrm{NO}\right)$ and conducting airway NO $\left(J_{\text {awNO }}^{\prime}\right)$ between groups, depending on the type of pulmonary pathology present. PAH subjects, particularly SSc-PAH subjects, appear to have higher exhaled alveolar NO than healthy subjects. In SSc-PAH subjects, increased conducting airway NO correlates with a reduced DLCO. However, SSc-ILD subjects had lower conducting airway NO than healthy subjects. BNP was higher in SSc-PAH subjects than SSc subjects without pulmonary involvement.

We found that median exhaled alveolar $\mathrm{NO}\left(C_{A} \mathrm{NO}\right)$ was highest in subjects with SSc. This aligns with the results of previous studies examining $C_{A} \mathrm{NO}$ values in subjects with SSc $[3,7,13-15,33,34]$. The median $C_{A} \mathrm{NO}$ value for the SSc-PAH group was significantly higher than that in control subjects. This demonstrates concurrent validity with the findings of two studies measuring $C_{A} \mathrm{NO}$ in individuals with SSc-PAH $[3,14]$. A possible mechanism for the observed increased $C_{A} \mathrm{NO}$ may include decreased diffusion of $\mathrm{NO}$ into the pulmonary circulation due to reduced pulmonary capillary volume, destruction of the vascular bed, alveolar/capillary block in ILD, or ventilation-perfusion mismatch. This hypothesis is supported by negative correlations between $C_{A} \mathrm{NO}$ and DLCO as reported by others $[7,35]$.

In SSc-PAH patients, increased conducting airway $\mathrm{NO}$ $\left(J_{\text {awNO }}^{\prime}\right)$ correlated with a reduced DLCO. This difference in conducting airway $\mathrm{NO}\left(J_{\mathrm{awNO}}^{\prime}\right)$ is illustrated in SSc-PAH patients with a DLCO greater than versus less than $60 \%$ predicted and supports the divergent validity of conducting airway NO testing [36]. The pathophysiologic relationship between conducting airway NO $\left(J_{\mathrm{awNO}}^{\prime}\right)$ and DLCO in SScPAH warrants further investigation, especially as DLCO is informative in the evaluation of $\mathrm{PAH}$.

The exploratory analyses suggest that SLE-PAH subjects have lower alveolar NO and higher conducting airway NO than SSc-PAH subjects whereas alveolar NO is more comparable between SSc-PAH and IPAH subjects. This suggests that although SLE-PAH subjects have similar mean pulmonary artery pressure elevations on cardiac catheterization as SSc$\mathrm{PAH}$ subjects, it may not be related to the same NO signaling abnormalities.

We explored the correlation between exhaled NO and age. We found no significant correlations with age across all the subgroups, suggesting a lack of age-dependent regulation of NO. We also explored differences in alveolar NO and conducting airway NO in solely female subjects, as there has been a suggestion that PAH pathology may be sex dependent. In our SSc-PAH cohort, we have previously demonstrated sex disparities in the frequency of $\mathrm{PAH}$, time to $\mathrm{PAH}$ diagnosis, $\mathrm{PAH}$ disease duration, and SSc disease burden; however male sex did not independently impact SSc-PAH survival [37]. The results of the subgroup analysis in the current study remained qualitatively unchanged but were not statistically significant. This is likely related to a reduction in sample size and resultant power. The small sample size limits the precision around our estimates. However, the sample size was sufficient to obtain between group differences to inform sample size and power estimation for clinical trials. It is important to note that the study definition of ILD was based on the CT SSc-ILD system [24]. This may have resulted in the inclusion of subjects with mild ILD compared to studies based on pulmonary function tests alone.

The trumpet model of axial diffusion (TMAD) did not perform well in this study. It may be that this model is not applicable to connective tissue disease subjects, despite being used by others [9]. Models of NO excretion in the airway, including the TMAD model, are theoretical and may not apply to all disease states. The TMAD model corrects observed values for the flow-independent NO parameters based on the trumpet geometry of the airways and also on axial diffusion, which is diffusion from terminal airways to the alveolar region against the direction of exhalation flow. Application of the TMAD model resulted in a small proportion of negative values for CANO in our cohort, which is physiologically impossible. This suggested that this model is not applicable to SSc. The reasons for this are unknown, but, possibly, the distortion of lung architecture has changed airway geometry, while the alveolar capillary block due to fibrosis may have reduced the impact of axial diffusion.

Compared to $F_{E} \mathrm{NO}$, assessing conducting airway and alveolar NO may allow us to discriminate more effectively between symptomatic subjects with SSc and associated $\mathrm{PAH}$ and/or ILD. In the setting of asthma, eNO measurement is used to clarify the cause of symptoms where more than one factor may be contributing to symptoms (including anxiety, obesity). Where symptoms and inflammation are discordant, eNO measurement provides useful information [38]. The CMAD models have provided evidence to support the presence of different microenvironments for NO production and metabolism in the conducting airways compared to the alveoli. This may ultimately be helpful in furthering our knowledge of the pathophysiology of PAH and ILD in SSc and also help to build on the hypothesis that PAH generally reflects a state of "NO deficiency." NO is currently targeted with phosphodiesterase type 5 inhibitors and stimulators of guanylate cyclase, yielding hemodynamic and symptomatic improvement in individuals with $\mathrm{PAH}[39,40]$. Improving 
TABLE 3: Median $C_{A} \mathrm{NO}$ and $J_{\text {awNO }}^{\prime}$ by subgroup.

\begin{tabular}{|c|c|c|c|c|c|c|c|}
\hline & $\mathrm{SSc}$ & SSc-PAH & SSc-ILD & SSc-PAH + ILD & SLE-PAH & IPAH & Control \\
\hline \multicolumn{8}{|l|}{ All subjects } \\
\hline$C_{A} \mathrm{NO} \mathrm{Ppb}$ median & 4.00 & 3.30 & 2.34 & 2.84 & 2.80 & 3.32 & 2.03 \\
\hline $\begin{array}{l}J_{\mathrm{awNO}}^{\prime} \mathrm{nL} / \mathrm{s} \text { median } \\
\text { Female subjects }\end{array}$ & 988.9 & 721.0 & 1009.5 & 1032.0 & 1138.3 & 952.0 & 1342.1 \\
\hline$C_{A} \mathrm{NO} \mathrm{Ppb}$ median & 4.00 & 3.30 & 2.34 & 2.09 & 2.80 & 3.32 & 2.47 \\
\hline$\underline{J_{\mathrm{awNO}}^{\prime} \mathrm{nL} / \mathrm{s} \text { median }}$ & 988.9 & 662 & 1009.5 & 1112.0 & 1138.3 & 924 & 1196 \\
\hline
\end{tabular}

Bold denotes significant finding, $\mathrm{Ppb}=$ parts per billion.

TABLE 4: Correlation between alveolar $\mathrm{NO}\left(\mathrm{C}_{A} \mathrm{NO}\right)$ and pulmonary function testing.

\begin{tabular}{lcccc}
\hline Group & TLC & FEV1 & FVC & DLCO \\
\hline SSc & $-0.32(-0.69,0.16)$ & $-0.40(-0.73,0.08)$ & $-0.39(-0.72,0.09)$ & $-0.44(-0.76,0.03)$ \\
SSc-PAH & $0.39(-0.62,0.91)$ & $0.06(-0.73,0.78)$ & $-0.26(-0.85,0.62)$ & $0.35(-0.65,0.90)$ \\
SLE-PAH & $-0.13(-0.91,0.84)$ & $0.75(-0.39,0.98)$ & $0.83(-0.19,0.99)$ & $-0.14(-0.91,0.85)$ \\
SSc-ILD & $-0.32(-0.98,0.93)$ & $-0.25(-0.97,0.94)$ & $0.25(-0.94,0.98)$ & $-0.95(-1.0,0.13)$ \\
IPAH & $-0.25(-0.88,0.70)$ & $-0.49(-0.89,0.32)$ & $-0.40(-0.86,0.42)$ & $0.30(-0.67,0.89)$ \\
\hline
\end{tabular}

None of the correlations were significant.

TABLE 5: Correlation between conducting airway $\mathrm{NO}\left(J_{\text {awNO }}^{\prime}\right)$ and pulmonary function testing.

\begin{tabular}{lcccr}
\hline Group & TLC & FEV1 & FVC & DLCO \\
\hline SSc & $0.46(-0.01,0.76)$ & $0.32(-0.17,0.68)$ & $0.05(-0.43,0.50)$ & $0.05(-0.42,0.51)$ \\
SSc-PAH & $-0.79(-0.98,0.04)$ & $-0.41(-0.89,0.50)$ & $-0.33(-0.87,0.56)$ & $-\mathbf{0 . 8 8}(-\mathbf{0 . 9 9},-\mathbf{0 . 2 6})$ \\
SLE-PAH & $0.42(-0.73,0.95)$ & $-0.44(-0.95,0.72)$ & $-0.10(-0.90,0.85)$ & $0.58(-0.62,0.97)$ \\
SSc-ILD & $0.23(-0.94,0.98)$ & $0.08(-0.95,0.97)$ & $-0.47(-0.99,0.90)$ & $0.59(-0.86,0.99)$ \\
IPAH & $-0.25(-0.88,0.70)$ & $-0.49(-0.89,0.33)$ & $-0.40(-0.86,0.42)$ & $0.30(-0.68,0.89)$ \\
\hline
\end{tabular}

Bold denotes significant correlations.

TABLE 6: Correlation between alveolar NO, conducting airway NO, and mean pulmonary artery pressure.

\begin{tabular}{lcc}
\hline Group & $\mathrm{mPAP}$ to $C_{A} \mathrm{NO}$ & $\mathrm{mPAP}$ to $J_{\text {awNO }}^{\prime}$ \\
\hline SSc-PAH & $0.42(-0.48,0.89)$ & $0.34(-0.56,0.87)$ \\
SLE-PAH & $0.47(-0.55,0.93)$ & $0.36(-0.64,0.91)$ \\
IPAH & $-0.06(-0.70,0.63)$ & $0.38(-0.37,0.83)$ \\
\hline
\end{tabular}

Note. Only subjects with PAH underwent right heart catheterization.

our understanding of the relationship between $\mathrm{eNO}$ and $\mathrm{PAH}$ in an etiology-specific manner is important, as the underlying balance between alveolar, vascular, and conducting airway eNO appears to vary with specific causes of PAH which may have implications for clinical management. However, currently, the performance of eNO determination at multiple flow rates is experimental and only suitable for academic centers with the equipment and knowledge required to perform these measures. The integration of eNO as a valuable marker in scleroderma pulmonary disease will require further validation and dissemination of knowledge.

\section{Conclusion}

We have demonstrated feasibility (ability to recruit and conduct these measurements in SSc subjects); identified that
CMAD modeling is preferred in SSc subjects; and generated pilot data for the magnitude of differences across lung diseases, patient subsets, and healthy controls, to base future sample size and power estimates. Our data supports discriminative validity of eNO in SSc lung disease. Our demonstration of feasibility, estimates of magnitude of differences between cases and controls, and demonstrable discriminative validity provide necessary prerequisite evaluation of a novel measure prior to its implementation as an outcome measure in clinical trials and observational studies of SSc lung disease.

\section{Abbreviations}

$C_{A}$ : Steady state alveolar concentration of $\mathrm{NO}$ $(\mathrm{nL} / \mathrm{L})$

$\mathrm{C}_{\mathrm{A}} \mathrm{NO}$ : Exhaled alveolar nitric oxide

cGMP: Cyclic $3^{\prime} 5^{\prime}$-monophosphate

CMAD: Compartment model of axial diffusion

eNO: $\quad$ Exhaled nitric oxide

$F_{E} \mathrm{NO}$ : Exhaled NO concentration (ppb)

ILD: Interstitial lung disease

IPAH: Idiopathic pulmonary arterial hypertension

$J_{\text {awNO }}^{\prime}$ : Total molar flux of NO in nanolitres/s (at an infinite Vexh) in $\mathrm{nL} / \mathrm{s}$ 
TABLE 7: Correlation between exhaled NO and age.

\begin{tabular}{lcc}
\hline Group & Alveolar NO $\left(C_{A} \mathrm{NO}\right) r(95 \% \mathrm{CI})$ & Conducting airway NO $\left(J_{\text {awNO }}^{\prime}\right) r(95 \% \mathrm{CI})$ \\
\hline All subjects & $0.16(-0.10,0.39)$ & $0.29(-0.08,0.59)$ \\
SSc & $0.25(-0.24,0.64)$ & $0.12(-0.36,0.56)$ \\
SSc-PAH & $-0.58(-0.93,0.30)$ & $0.48(-0.43,0.91)$ \\
SSc-ILD & $0.78(-0.72,1.00)$ & $-0.92(-1.0,0.33)$ \\
SLE-PAH & $-0.56(-0.94,0.46)$ & $-0.21(-0.87,0.73)$ \\
IPAH & $-0.60(-0.90,0.11)$ & $0.13(-0.58,0.73)$ \\
Healthy controls & $-0.07(-0.67,0.59)$ & $0.41(-0.29,0.83)$ \\
\hline
\end{tabular}

NOS: Nitric oxide synthase

PAH: Pulmonary arterial hypertension

Ppb: $\quad \mathrm{nL} / \mathrm{L}\left(1 \times 10^{-9}\right)$

SLE: Systemic lupus erythematosus

SSc: $\quad$ Systemic sclerosis

TMAD: Trumpet model of axial diffusion

$V_{\text {exh }}: \quad$ Flow rate $(\mathrm{mL} / \mathrm{s})$

$V_{\mathrm{NO}}: \quad$ NO output $(\mathrm{pL} / \mathrm{s})$.

\section{Competing Interests}

Dr. Johnson is supported by the Canadian Institutes of Health Research New Investigator Award, the Oscar and Eleanor Markovitz Scleroderma Research Fund and the Freda Fejer Fund for Scleroderma Research. Dr. Granton has received funding from Pfizer for research support for an investigator led research study, Actelion as a site investigator for clinical trials, member of Data Safety Monitoring Committee and for support of education programs through the hospital foundation, and Ikaria as a site investigator for a clinical trial and member of steering committee. No nonfinancial conflict of interests exists for any of the authors.

\section{References}

[1] A. J. MacGregor, R. Canavan, C. Knight et al., "Pulmonary hypertension in systemic sclerosis: risk factors for progression and consequences for survival," Rheumatology, vol. 40, no. 4, pp. 453-459, 2001.

[2] S. R. Johnson and J. T. Granton, "Pulmonary hypertension in systemic sclerosis and systemic lupus erythematosus," European Respiratory Review, vol. 20, no. 122, pp. 277-286, 2011.

[3] G. Rolla, P. Colagrande, E. Scappaticci et al., "Exhaled nitric oxide in systemic sclerosis: relationships with lung involvement and pulmonary hypertension," The Journal of Rheumatology, vol. 27, no. 7, pp. 1693-1698, 2000.

[4] G. Rolla, P. Colagrande, L. Brussino, C. Bucca, M. T. Bertero, and F. Caligaris-Cappio, "Exhaled nitric oxide and pulmonary response to iloprost in systemic sclerosis with pulmonary hypertension," Lancet, vol. 351, no. 9114, pp. 1491-1492, 1998.

[5] Y. Kawaguchi, Y. Kawaguchi, M. Hara et al., "NOS2 polymorphisms associated with the susceptibility to pulmonary arterial hypertension with systemic sclerosis: contribution to the transcriptional activity," Arthritis Research \& Therapy, vol. 8, no. 4, article R104, 2006.

[6] S. A. Kharitonov, J. B. Cailes, C. M. Black, R. M. Du Bois, and P. J. Barnes, "Decreased nitric oxide in the exhaled air of patients with systemic sclerosis with pulmonary hypertension," Thorax, vol. 52, no. 12, pp. 1051-1055, 1997.

[7] R. E. Girgis, M. K. Gugnani, J. Abrams, and M. D. Mayes, "Partitioning of alveolar and conducting airway nitric oxide in scleroderma lung disease," American Journal of Respiratory and Critical Care Medicine, vol. 165, no. 12, pp. 1587-1591, 2002.

[8] M. Malerba, A. Radaeli, B. Ragnoli et al., "Exhaled nitric oxide levels in systemic sclerosis with and without pulmonary involvement," Chest, vol. 132, no. 2, pp. 575-580, 2007.

[9] K. P. Tiev, J. Coste, M. Ziani, F. Aubourg, J. Cabane, and A. T. Dinh-Xuan, "Diagnostic value of exhaled nitric oxide to detect interstitial lung disease in systemic sclerosis," Sarcoidosis Vasculitis and Diffuse Lung Diseases, vol. 26, no. 1, pp. 32-38, 2009.

[10] C. M. Hart, "Nitric oxide in adult lung disease," Chest, vol. 115, no. 5, pp. 1407-1417, 1999.

[11] S. A. Kharitonov and P. J. Barnes, "Exhaled markers of pulmonary disease," American Journal of Respiratory and Critical Care Medicine, vol. 163, no. 7, pp. 1693-1722, 2001.

[12] P. Paredi, S. A. Kharitonov, S. Loukides, P. Pantelidis, R. M. Du Bois, and P. J. Barnes, "Exhaled nitric oxide is increased in active fibrosing alveolitis," Chest, vol. 115, no. 5, pp. 1352-1356, 1999.

[13] K. P. Tiev, T. Hua-Huy, S. Rivière et al., "High alveolar concentration of nitric oxide is associated with alveolitis in scleroderma," Nitric Oxide - Biology and Chemistry, vol. 28, pp. 65-70, 2013.

[14] K. P. Tiev, N.-N. Le-Dong, S. Duong-Quy, T. Hua-Huy, J. Cabane, and A. T. Dinh-Xuan, "Exhaled nitric oxide, but not serum nitrite and nitrate, is a marker of interstitial lung disease in systemic sclerosis," Nitric Oxide: Biology and Chemistry, vol. 20, no. 3, pp. 200-206, 2009.

[15] K. P. Tiev, J. Cabane, F. Aubourg et al., "Severity of scleroderma lung disease is related to alveolar concentration of nitric oxide," European Respiratory Journal, vol. 30, no. 1, pp. 26-30, 2007.

[16] K. P. Tiev, T. Hua-Huy, A. Kettaneh et al., "Alveolar concentration of nitric oxide predicts pulmonary function deterioration in scleroderma," Thorax, vol. 67, no. 2, pp. 157-163, 2012.

[17] S. R. Johnson, D. Khanna, Y. Allanore, M. Matucci-Cerinic, and D. E. Furst, "Systemic sclerosis trial design moving forward," Journal of Scleroderma and Related Disorders, vol. 1, no. 2, pp. 177-180, 2016.

[18] S. R. Johnson, J. T. Granton, G. A. Tomlinson et al., "Warfarin in systemic sclerosis-associated and idiopathic pulmonary arterial hypertension. A bayesian approach to evaluating treatment for uncommon disease," Journal of Rheumatology, vol. 39, no. 2, pp. 276-285, 2012.

[19] H. Hussein, P. Lee, C. Chau, and S. R. Johnson, "The effect of male sex on survival in systemic sclerosis," The Journal of Rheumatology, vol. 41, no. 11, pp. 2193-2200, 2014. 
[20] F. Van Den Hoogen, D. Khanna, J. Fransen et al., "2013 classification criteria for systemic sclerosis: an american college of rheumatology/European league against rheumatism collaborative initiative," Arthritis and Rheumatism, vol. 65, no. 11, pp. 2737-2747, 2013.

[21] E. M. Tan, A. S. Cohen, J. F. Fries et al., “The 1982 revised criteria for the classification of systemic lupus erythematosus," Arthritis \& Rheumatism, vol. 25, no. 11, pp. 1271-1277, 1982.

[22] M. C. Hochberg, "Updating the American College of Rheumatology revised criteria for the classification of systemic lupus erythematosus," Arthritis and Rheumatism, vol. 40, no. 9, p. 1725, 1997.

[23] L. J. Rubin, "Introduction. Diagnosis and management of pulmonary arterial hypertension: ACCP evidence-based clinical practice guidelines," Chest, vol. 126, no. 1, pp. 7S-10S, 2004.

[24] N. S. L. Goh, S. R. Desai, S. Veeraraghavan et al., "Interstitial lung disease in systemic sclerosis: a simple staging system," American Journal of Respiratory and Critical Care Medicine, vol. 177, no. 11, pp. 1248-1254, 2008.

[25] M. Högman, N. Drca, C. Ehrstedt, and P. Meriläinen, "Exhaled nitric oxide partitioned into alveolar, lower airways and nasal contributions," Respiratory Medicine, vol. 94, no. 10, pp. 985991, 2000.

[26] N. M. Tsoukias and S. C. George, "A two-compartment model of pulmonary nitric oxide exchange dynamics," Journal of Applied Physiology, vol. 85, no. 2, pp. 653-666, 1998.

[27] R. A. Jorres, "Modelling the production of nitric oxide within the human airways," The European Respiratory Journal, vol. 16, no. 3, pp. 555-560, 2000.

[28] P. E. Silkoff, J. T. Sylvester, N. Zamel, and S. Permutt, "Airway nitric oxide diffusion in asthma: role in pulmonary function and bronchial responsiveness," American Journal of Respiratory and Critical Care Medicine, vol. 161, no. 4, part 1, pp. 1218-1228, 2000.

[29] A. P. Pietropaoli, I. B. Perillo, A. Torres et al., "Simultaneous measurement of nitric oxide production by conducting and alveolar airways of humans," Journal of Applied Physiology, vol. 87, no. 4, pp. 1532-1542, 1999.

[30] P. Condorelli, H.-W. Shin, A. S. Aledia, P. E. Silkoff, and S. C. George, "A simple technique to characterize proximal and peripheral nitric oxide exchange using constant flow exhalations and an axial diffusion model," Journal of Applied Physiology, vol. 102, no. 1, pp. 417-425, 2007.

[31] N. K. Kozij, J. T. Granton, P. E. Silkoff, J. Thenganatt, S. Chakravorty, and S. R. Johnson, "Exhaled nitric oxide in systemic sclerosis lung disease," Arthritis \& Rheumatology, vol. 67, supplement 10, 2015.

[32] P. E. Silkoff, "Exhaled nitric oxide and asthma," The New England Journal of Medicine, vol. 353, no. 7, pp. 732-733, 2005.

[33] D. M. Wuttge, G. Bozovic, R. Hesselstrand et al., "Increased alveolar nitric oxide in early systemic sclerosis," Clinical and Experimental Rheumatology, vol. 28, no. 5, supplement 62, pp. S5-S9, 2010.

[34] T. Hua-Huy, K. P. Tiev, C. Chéreau, S. Duong-Quy, J. Cabane, and A. T. Dinh-Xuan, "Increased alveolar concentration of nitric oxide is related to serum-induced lung fibroblast proliferation in patients with systemic sclerosis," The Journal of Rheumatology, vol. 37, no. 8, pp. 1680-1687, 2010.

[35] L. Lehtimäki, H. Kankaanranta, S. Saarelainen et al., "Extended exhaled NO measurement differentiates between alveolar and bronchial inflammation," American Journal of Respiratory and Critical Care Medicine, vol. 163, no. 7, pp. 1557-1561, 2001.
[36] D. L. Streiner and G. R. Norman, Health Measurement Scales. A Practical Guide to Their Development and Use, Oxford Universit Press, Oxford, UK, 4th edition, 2008.

[37] C. R. Pasarikovski, J. T. Granton, A. M. Roos et al., "Sex disparities in systemic sclerosis-associated pulmonary arterial hypertension: a cohort study," Arthritis Research \& Therapy, vol. 18, article 30, 2016.

[38] P. J. Barnes, R. A. Dweik, A. F. Gelb et al., "Exhaled nitric oxide in pulmonary diseases: a comprehensive review," Chest, vol. 138, no. 3, pp. 682-692, 2010.

[39] S. L. Archer and E. D. Michelakis, "Phosphodiesterase type 5 inhibitors for pulmonary arterial hypertension," The New England Journal of Medicine, vol. 361, no. 19, pp. 1864-1871, 2009.

[40] H.-A. Ghofrani, N. Galiè, F. Grimminger et al., "Riociguat for the treatment of pulmonary arterial hypertension," The New England Journal of Medicine, vol. 369, no. 4, pp. 330-340, 2013. 


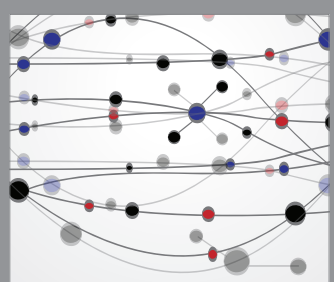

The Scientific World Journal
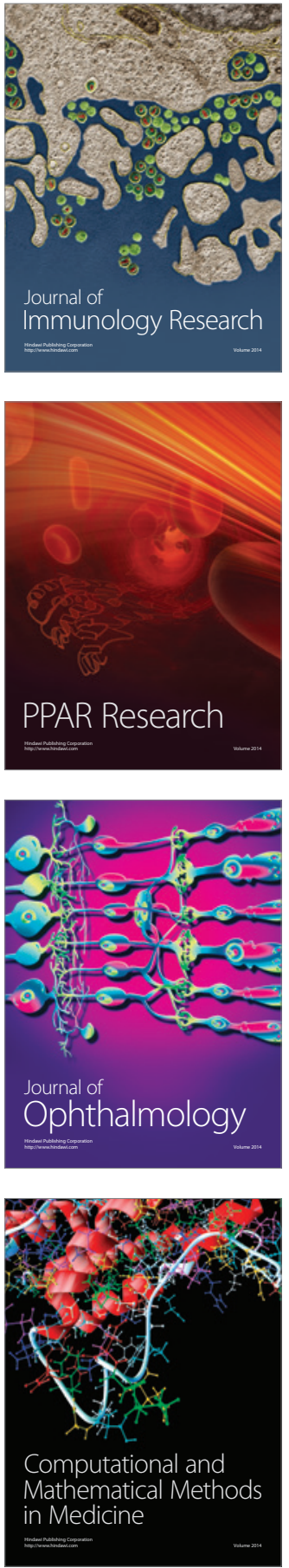

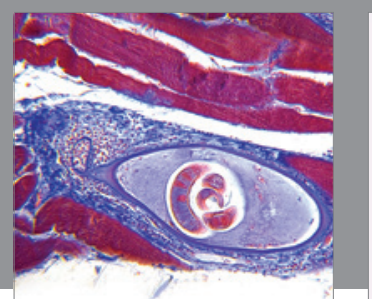

Gastroenterology Research and Practice
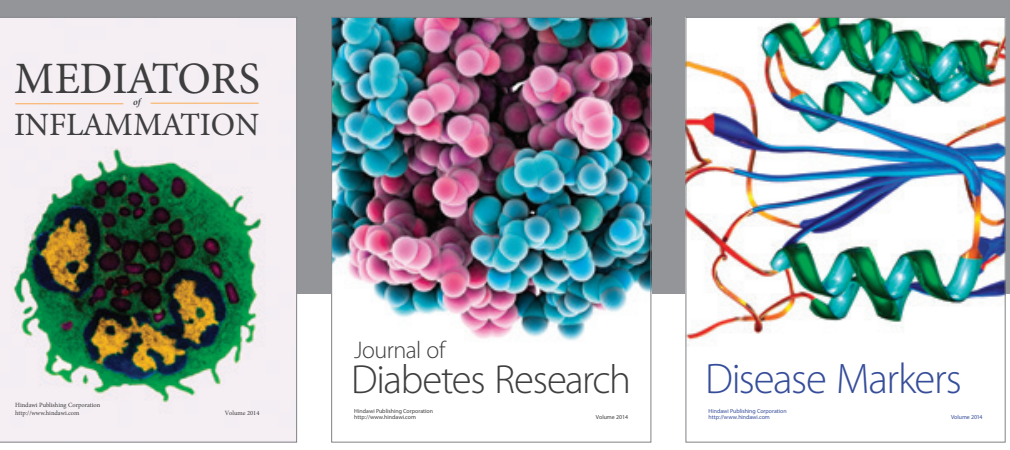

Disease Markers

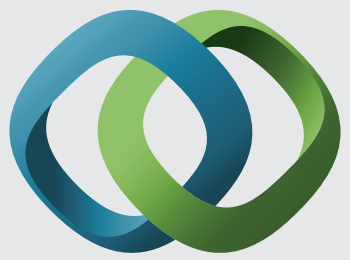

\section{Hindawi}

Submit your manuscripts at

https://www.hindawi.com
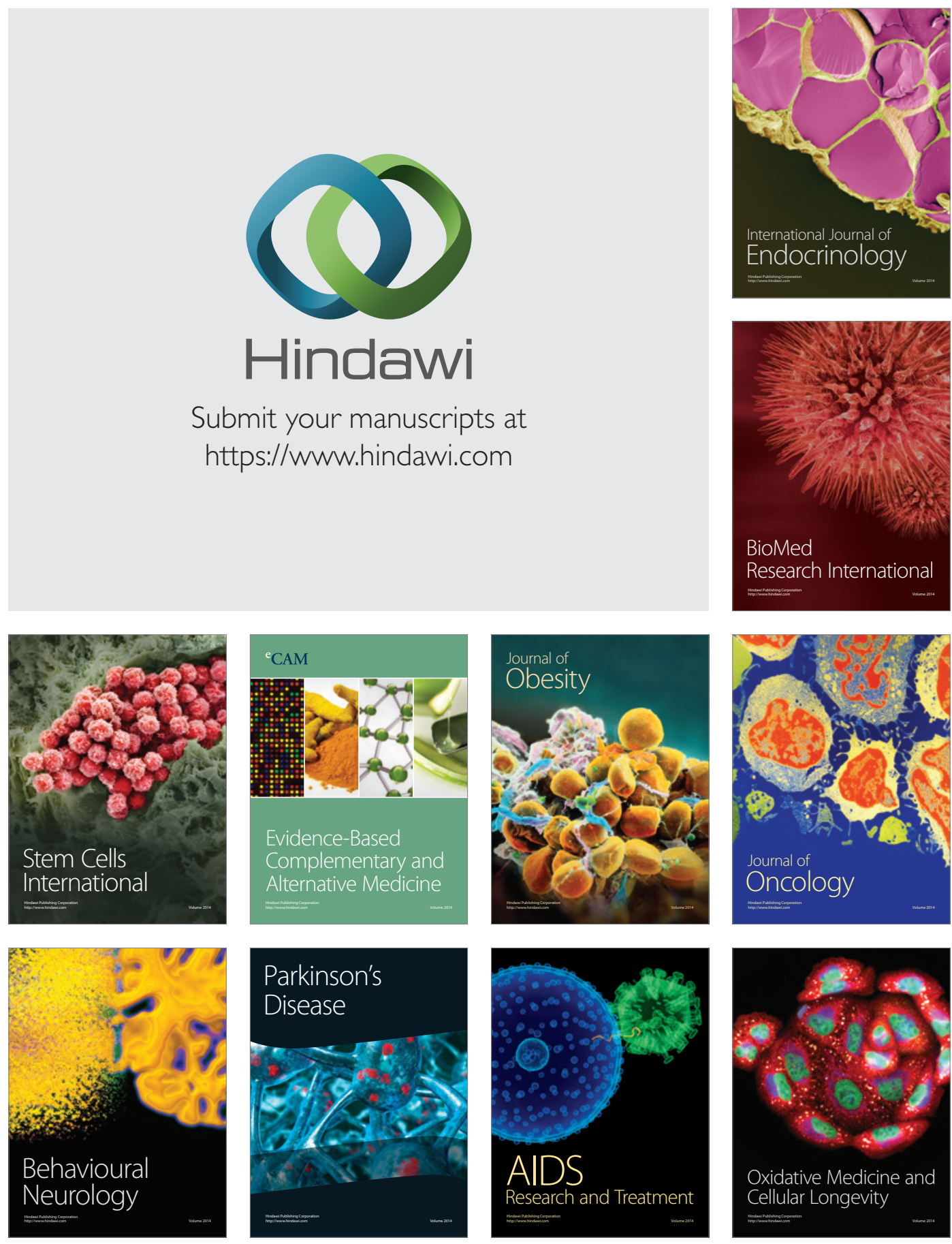